\title{
Improvements of Functional Activity and Pain Relief through Stabilization Exercise in Capsulorrhaphy Surgery of Shoulder Dislocation Patients
}

\author{
Youn-Bum Sung ${ }^{1}$, Young-Han Park ${ }^{2}$ and Jung-Ho Lee 3* $^{3}$ \\ ${ }^{1}$ Department of Physical Therapy, College of Rehabilitation Science, Daegu \\ University, Republic of Korea \\ ${ }^{2}$ Department of Physical Therapy, Korea National University of Transportation, \\ Republic of Korea \\ ${ }^{3}$ Department of Physical Therapy, School of Medical \& Public Health, Kyungdong \\ University, Republic of Korea \\ 1 playeryoon@hanmail.net, ${ }^{2}$ yhpark@ut.ac.kr, ${ }^{3}$ ljhcivapt@naver.com
}

\begin{abstract}
The purpose of this study cares to investigate effect of shoulder stabilization exercise at the pain control, function and range of motion of shoulder girdle after surgery of shoulder dislocation patients. The subjects were 30 patients who operated on capsulorrhaphy surgery of shoulder dislocation patients. They were assigned by random sampling to an experimental group $(n=15)$ to which stabilization exercise was applied and a control group $(n=15)$ to which ordinary physical treatment was applied. To evaluate the degree of pain prior to and after the treatment, a $100 \mathrm{~mm}$ visual analogue scale (VAS) was used. The Constant-Murley Scale (CMS) and simple shoulder test (SST) was used to determine the function and condition of the shoulder joints of the subjects. To determine the range of motion, a Dartfish program was used. The results of comparison of the therapeutic effect in the experimental and control groups revealed significant differences in active abduction, SST, and power component of the CMS. The results suggest that shoulder stabilization exercise positively affects pain alleviation and functional recovery in shoulder dislocation patients.
\end{abstract}

Key words: Swiss ball, capsulorrhaphy surgery, stabilization exercise

\section{Introduction}

A shoulder joint that is a special joint supported by muscles and tendons in body has a wide range of motion but joint stability has disadvantage because humerus head's $1 / 3$ joint with glenoid fossa. A shoulder joint has disadvantage of injury, and dislocation occurs the most frequently in the body [1].

Anterior dislocation is the most type in the dislocation type of shoulder joint [2]. Anterior dislocation occurs by direct trauma or falling down with arms stretching. Injury type is Bankart lesion and Hill-Sachs lesion. Bankart lesion is that glenoidal labrum or capsule detached from anterior glenoidal rim detected by arthroscope or magnetic resonance image. Hill-Sachs lesion is cartilage lesion because posterolateral part of humeral head is bumped into gleniod fossa. Hill-Sachs lesion can be detected general Xray flim [3]. Treatment for dislocation of shoulder is surgical or non-surgical treatment. Surgical treatment is more effective to prevent re-dislocation than non-surgical treatment [4].

There are many soft tissues contributing shoulder stability such as articular capsule, labrum, and muscles. Shoulder dislocation generally leads to injury of soft tissues and tear of long head of biceps brachii. Therefore, surgeries are generally Bankart repair, 
electrothermally assisted capsulorrhaphy [5]. After shoulder surgery, it is important to improve limited range of motion and muscle power. In the early stage, it is generally used cold therapy to control pain, and heat therapy to release soft tissue and then, it is advisable to intensify muscles [6]. Shoulder stabilization exercise which is safety and don't apply hard attack on the shoulder is good to early stage patients after surgery [7]. Therapist has used shoulder stabilization exercise to fix abnormal state of scapula position, movement and functional disorders, and also shoulder stabilization exercise may give stability to shoulder girdle $[8,9]$.

Swiss ball is widely used to train stabilization muscles [10]. Marshall(2005) reported that it is considerable effect stabilization exercise using swiss ball to induce rectus abdominis [11]. In addition, it is showed that trapezius activity is higher using swiss ball than conventional physical therapy [12]. Furthermore, closed kinetic chain exercise is more effective to stimulate proprioception and muscle function than open kinetic chain exercise [13].

Previous researches are about comparison of recurrence rate between surgical therapy and non-surgical therapy. There are few studies to assess function and range of motion and pain control of shoulder joint after surgery of shoulder dislocation patients. The purpose of this study cares to investigate effect of shoulder stabilization exercise at the pain control, function and range of motion of shoulder girdle after surgery of shoulder dislocation patients.

\section{Methods}

\section{1. Subject and Intervention Procedure}

The subjects were 30 patients who were operated on capsulorrhaphy surgery of shoulder dislocation patients. They were assigned by random sampling to an experimental group $(\mathrm{n}=15)$ to which stabilization exercise was applied and a control group $(\mathrm{n}=15)$ to which ordinary physical treatment was applied (Table 1). Experimental group and control group were received heat therapy during 20 minutes, TENS during 10 minutes, and laser during 10 minutes, and then each group was received different therapy. Control group was received conventional physical therapy, and experimental group was received shoulder stabilization exercise. The study subjects provided written informed consent prior to participation according to the ethical standards of the Declaration of Helsinki.

Table 1. General Characteristics of the Subjects (Mean \pm SD)

\begin{tabular}{|c|c|c|c|}
\hline & Experimental group $(\mathrm{n}=15)$ & Control group $(\mathrm{n}=15)$ & $p$ \\
\hline Age $(\mathrm{yr})$ & $59.73 \pm 6.09$ & $61.20 \pm 4.81$ & .470 \\
\hline Weight $(\mathrm{kg})$ & $58.27 \pm 6.46$ & $57.87 \pm 5.84$ & .860 \\
\hline Height $(\mathrm{cm})$ & $158.33 \pm 7.98$ & $160.40 \pm 5.67$ & .420 \\
\hline
\end{tabular}

\subsection{Assessment}

To evaluate the degree of pain prior to and after the treatment, a $100 \mathrm{~mm}$ visual analogue scale (VAS) was used. The patients were asked to mark the intensity of pain they felt when they watched the table. The Constant-Murley Scale (CMS), which is a well-known, standardized clinical evaluation method, was used to evaluate the functions of the shoulder joints. Evaluation items included the degree of pain, range of motion, activities of daily living, muscle power, and total score. The 100 points consisted of subjective elements (35 points) and objective elements (65 points). The subjective elements were composed of the degree of pain (15 points) and activities of daily living (20 points), and the objective elements were comprised of the range of motion (flexion, abduction, external rotation, internal rotation: a total of 40 points) and muscle power (25 points); the higher each item or total score was, the better the function was considered. 
To determine the range of motion, a Dartfish program (Pro Suite, Dfkorea, Korea) was used to measure the passive flexion, active flexion, passive abduction, and active abduction. In order to prevent damage due to external rotation, external rotation angle was not measured. The simple shoulder test (12 items) was used to determine the condition of the shoulder joints of the subjects.

\subsection{Intervention}

The control group was received conventional physical therapy (ICT during 20 minutes and ultrasound 10 minutes) after heat therapy during 20 minutes, TENS during 10 minutes, laser therapy 10 minutes to control pain and enhance shoulder function.

The experimental group was received conventional physical therapy such as heat therapy during 20 minutes, TENS during 10 minutes, laser therapy during 10mutes, and then accomplished shoulder stabilization exercise. Shoulder stabilization exercise was that the subjects lied on the swiss ball with knee 90 degree flexion and the swiss ball was located below between both scapular bones. The subjects conducted adduction and retraction of scapula to fix the swiss ball. The subjects with low back pain put on the medical belly band to release compression of low back. Also, at standing position, the subjects leaned toward the swiss ball which is fixed by wrist of the subjects with the wall flexing elbow joint 90 degree. The therapist commanded the subjects to conduct shoulder external rotation and then maintain that position.

One set of all exercises was composed of 10 times such as 10 seconds maintain and 5 seconds break. Each exercise is composed of 3 sets and between each set, subject rested 3 minutes. Both groups were received physical therapy 3 times a week, for 6 weeks, for total 18 times.

\subsection{Statistical Analysis}

In the data processing, descriptive statistics were used to detect general characteristics of the subjects. A paired t-test was employed to examine differences in pain alleviation and functional improvement of the experimental group and the control group before and after the treatment. The independent t-test was used for inter-group comparison. For the data analysis, Win-SPSS Version 20.0 was used, and a significance level was set at $\alpha=$ 0.05 .

\section{Results}

There were significant differences in active flexion, active abduction, and passive flexion in the experimental group $(\mathrm{p}<0.05)$, and there were significant differences in all items of the CMS ( $p<0.05$ ), but passive abduction, VAS, and SST did not show a significant difference (Table 2)(Table 3). This means that the stabilization exercise could increase the ROM and function, reduce the pain of shoulder.

Table 2. Comparative Analysis of the Experimental Group before and after the Treatment (Mean \pm SD)

\begin{tabular}{|c|c|c|c|c|}
\hline & $\begin{array}{c}\text { Experimental group } \\
(\mathrm{n}=15)\end{array}$ & $\begin{array}{c}\text { Control group } \\
(\mathrm{n}=15)\end{array}$ & $t$ & $p$ \\
\hline Active Flexion & $77.33 \pm 11.47$ & $86.67 \pm 13.18$ & -2.068 & $.048^{*}$ \\
\hline Active Abduction & $73.33 \pm 5.56$ & $83.00 \pm 7.51$ & -4.005 & $.000^{*}$ \\
\hline Passive Flexion & $89.67 \pm 9.72$ & $99.33 \pm 13.07$ & -2.298 & $.029^{*}$ \\
\hline Passive Abduction & $98.33 \pm 9.75$ & $101.33 \pm 10.26$ & -.821 & .419 \\
\hline Visual Analog Scale & $57.33 \pm 12.80$ & $45.33 \pm 13.56$ & 2.493 & .019 \\
\hline$p<0.05$
\end{tabular}


There were significant differences in active abduction in the control group $(\mathrm{p}<0.05)$; there was no significant difference in the active and passive flexion, passive abduction, VAS and SST, also each items of CMS; but CMS total score showed a significant difference $(\mathrm{p}<0.05)$ (Table 4) (Table 5).

In addition, the results of comparison of the therapeutic effect in the experimental and control groups revealed significant differences in active abduction, SST, and power component of the CMS (Table 6) (Table 7). This means that the stabilization exercise more effective to improve ROM, function, muscle power than conventional therapy.

Table 3. Comparative Analysis of the Experimental Group before and after the Treatment (Mean \pm SD)

\begin{tabular}{|c|c|c|c|c|c|}
\hline & & $\begin{array}{l}\text { Experimental group } \\
(\mathrm{n}=15)\end{array}$ & $\begin{array}{c}\text { Control group } \\
(\mathrm{n}=15)\end{array}$ & $t$ & $p$ \\
\hline \multicolumn{2}{|c|}{ Simple Shoulder Test } & $10.80 \pm 1.52$ & $9.53 \pm 2.00$ & 1.955 & .061 \\
\hline \multirow{5}{*}{ CMS } & Pain & $6.33 \pm 2.97$ & $8.67 \pm 2.97$ & -2.153 & $.040^{*}$ \\
\hline & ADL & $11.73 \pm 1.83$ & $14.53 \pm 2.56$ & -3.446 & $.002^{*}$ \\
\hline & ROM & $17.60 \pm 5.19$ & $22.27 \pm 5.44$ & -2.402 & $.023^{*}$ \\
\hline & Power & $13.47 \pm 2.80$ & $17.73 \pm 3.03$ & -4.002 & $.000^{*}$ \\
\hline & Total & $49.47 \pm 9.46$ & $64.27 \pm 9.18$ & -4.348 & $.000^{*}$ \\
\hline
\end{tabular}

$p<0.05, \mathrm{CMS}=$ Constant-Murley Scale, ADL =Activities of Daily Living, ROM = Range Of Motion

Table 4. Comparative Analysis of the Control Group before and after the Treatment (Mean \pm SD)

\begin{tabular}{|c|c|c|c|c|}
\hline & $\begin{array}{c}\text { Experimental group } \\
(\mathrm{n}=15)\end{array}$ & $\begin{array}{c}\text { Control group } \\
(\mathrm{n}=15)\end{array}$ & $t$ & $p$ \\
\hline Active Flexion & $77.33 \pm 14.38$ & $85.33 \pm 15.41$ & -1.470 & .153 \\
\hline Active Abduction & $77.67 \pm 9.04$ & $94.33 \pm 9.98$ & -4.795 & $.000^{*}$ \\
\hline Passive Flexion & $93.00 \pm 15.68$ & $101.67 \pm 16.00$ & -1.499 & .145 \\
\hline Passive Abduction & $87.67 \pm 13.61$ & $95.67 \pm 12.94$ & -1.650 & .110 \\
\hline Visual Analog Scale & $61.33 \pm 11.87$ & $50.67 \pm 14.13$ & 2.239 & .033 \\
\hline Simple Shoulder Test & $10.07 \pm 1.53$ & $10.13 \pm 1.25$ & -.131 & .897 \\
\hline
\end{tabular}

Table 5. Comparative Analysis of the Control Group before and after the Treatment (Mean \pm SD)

\begin{tabular}{|c|c|c|c|c|c|}
\hline & & $\begin{array}{c}\text { Experimental group } \\
(\mathrm{n}=15)\end{array}$ & $\begin{array}{c}\text { Control group } \\
(\mathrm{n}=15)\end{array}$ & $t$ & $p$ \\
\hline \multicolumn{2}{|c|}{ Simple Shoulder Test } & $10.07 \pm 1.53$ & $10.13 \pm 1.25$ & -.131 & .897 \\
\hline \multirow{5}{*}{ CMS } & Pain & $7.67 \pm 3.20$ & $9.00 \pm 2.07$ & -1.355 & .186 \\
\hline & ADL & $11.73 \pm 2.12$ & $13.33 \pm 2.35$ & -1.958 & .060 \\
\hline & ROM & $19.47 \pm 5.37$ & $21.87 \pm 5.21$ & -1.243 & .224 \\
\hline & Power & $14.80 \pm 3.26$ & $16.40 \pm 3.09$ & -1.381 & .178 \\
\hline & Total & $52.67 \pm 10.05$ & $61.67 \pm 9.97$ & -2.462 & $.020^{*}$ \\
\hline
\end{tabular}

$p<0.05, \mathrm{CMS}=$ Constant-Murley Scale, ADL =Activities of Daily Living, ROM = Range Of Motion 
Table 6. Comparative Analysis between the Groups (Mean \pm SD)

\begin{tabular}{|c|c|c|c|c|}
\hline & $\begin{array}{c}\text { Experimental group } \\
(\mathrm{n}=15)\end{array}$ & $\begin{array}{c}\text { Control group } \\
(\mathrm{n}=15)\end{array}$ & $t$ & $p$ \\
\hline Active Flexion & $9.33 \pm 4.95$ & $8.00 \pm 3.16$ & .879 & .387 \\
\hline Active Abduction & $9.67 \pm 3.99$ & $16.67 \pm 4.88$ & -4.299 & $.000^{*}$ \\
\hline Passive Flexion & $9.67 \pm 6.67$ & $8.67 \pm 3.52$ & .513 & .612 \\
\hline Passive Abduction & $3.00 \pm 10.66$ & $8.00 \pm 3.16$ & -1.742 & .092 \\
\hline Visual Analog Scale & $-12.00 \pm 4.14$ & $-10.67 \pm 4.58$ & -.837 & .410 \\
\hline Simple Shoulder Test & $-1.27 \pm 1.16$ & $0.07 \pm 1.44$ & -2.793 & $.009^{*}$ \\
\hline$p<0.05$ & & &
\end{tabular}

Table 7. Comparative Analysis between the Groups (Mean \pm SD)

\begin{tabular}{|c|c|c|c|c|c|}
\hline \multicolumn{2}{|c|}{} & $\begin{array}{c}\text { Experimental group } \\
(\mathrm{n}=15)\end{array}$ & $\begin{array}{c}\text { Control group } \\
(\mathrm{n}=15)\end{array}$ & $t$ & $p$ \\
\hline \multicolumn{2}{|c|}{ Simple Shoulder Test } & $-1.27 \pm 1.16$ & $0.07 \pm 1.44$ & -2.793 & $.009^{*}$ \\
\hline \multirow{5}{*}{ CMS } & Pain & $2.33 \pm 2.58$ & $1.33 \pm 3.51$ & .887 & .382 \\
\cline { 2 - 6 } & ADL & $2.80 \pm 2.48$ & $1.60 \pm 2.29$ & 1.375 & .180 \\
\cline { 2 - 6 } & ROM & $4.67 \pm 4.19$ & $2.40 \pm 1.88$ & 1.913 & .066 \\
\cline { 2 - 6 } & Power & $4.27 \pm 3.90$ & $1.60 \pm 2.47$ & 2.237 & $.033^{*}$ \\
\cline { 2 - 6 } & Total & $14.80 \pm 12.58$ & $9.00 \pm 11.00$ & 1.344 & .190 \\
\hline
\end{tabular}

$p<0.05, \mathrm{CMS}=$ Constant-Murley Scale, ADL =Activities of Daily Living, ROM = Range Of Motion

\section{Discussion}

This study investigated the effect of shoulder stabilization exercise on the shoulder dislocation patients undergone capsulorrhaphy surgery about pain and functional recovery. Shoulder joint has a wide range of motion while dislocation the most frequently comes up in the body. $95 \%$ of first time dislocation patients were caused by trauma or falling [14]. If patients are not applied therapy in the early stage after dislocation, recurrence rate is high up to $95 \%$ and also shoulder pain or functional limit has an large influence on activities of daily living with causing lowering quality of life [1, 15].

Bottoni(2002) investigated recurrence of shoulder dislocation patients [16]. This study reported that non-surgical treatment patent's recurrence rate is 9 of $12(75 \%)$, and arthroscophic surgery is 1 of $9(11.1 \%)$. However, patients who were take surgery have some problems with activities of daily living because of limit of range of motion. Therefore, therapists should focus on increasing range of motion of shoulder with controlling pain and strengthening surrounding muscles to prevent re-dislocation of shoulder. Therefore, it is important to rehabilization after surgery because recurrence rate is not zero.

In shoulder girdle whole joints such as scapulothoracic joint, glenohumeral joint, acromioclavicular joint and sternoclavicular joint. Movement of shoulder is completed as movement of each joint [17]. Because shoulder joint has the largest movement and is unstable joint, stability of shoulder joint is augmented by muscles such as rotate cuffs [18]. Stabilization is ability to consciously or unconsciously control fine movement of joint. Stability of scapular bone causes influence on normal movement of shoulder girdle [19]. Scapula is attached many muscles to assist stability of shoulder girdle, sternoclavicular joint, scapulothoracic joint, which is false joint, should be established other joints above all [20].

Stability of scapula provides primary stability of shoulder girdle, and fixes abnormal movement [18]. And then, external rotation of glenohumeral joint is considered. External rotation is essential movement at flexion and abduction, so if the patient has a problem 
with movement of external rotation, it is easy to evoke pain and hard to normally move [21]. Therefore, after establishment of stability of scapulothoracic joint exercise of other movement such as external rotation, flexion, extension, adduction, and abduction should be conducted at a proper time [22].

Scapulothoracic joints, virtual joint, play essential role in movement and stability of shoulder girdle compared with other joints, so stability of scapulothoracic joints is most important in the shoulder girdle [23]. Therefore above all, it is important unto shoulder dislocation patients getting stability of scapulothoracic joint using shoulder stabilization exercise, and surrounding muscles such as teres major, teres minor, subscapularis, rhomboids, serratus anterior and trapezius lower fiber may prevent atrophy and shortening and strengthen muscle power [24].

De Oliveira(2008) reported that exercise of shoulder and arm using swiss ball enhance activity of trapezius [12]. Marshall(2005) showed that core stabilization exercise using swiss ball make considerable increase of activities of rectus abdominis [11]. Also, it is reported that stabilization exercise is effective on pain control and functional recovery of patient during long term [25-27]. That is, the stabilization exercise of the shoulders have a positive effect on the pain and function. Clinicians, the patients who received damaged of shoulder will need stabilization exercise.

In this study, the use of stabilization exercise to treat shoulder dislocation in capsulorrhaphy patients reduced their pain and had positive effects on their functional recovery. However, this study had some limitations, namely, a short study period and a small number of subjects. More efficient and systematic research to shed light on the role of stabilization exercise is needed.

\section{Conclusions}

In this study, to investigate effect of shoulder stabilization exercise at the pain control, function and range of motion of shoulder girdle after surgery of shoulder dislocation patients. Experimental group and control group were received heat therapy during 20 minutes, TENS during 10 minutes, and laser during 10 minutes, and then each group was received different therapy. Control group was received conventional physical therapy, and experimental group was received shoulder stabilization exercise. the results of comparison of the therapeutic effect in the experimental and control groups revealed significant differences in active abduction, SST, and power component of the CMS. This means that the stabilization exercise more effective to improve ROM, function, muscle power than conventional therapy. In addition, this intervention is an effective physical therapy, and further study is needed to increase the clinical application.

\section{References}

[1] S. Cutts, M. Prempeh and S. Drew, “Anterior shoulder dislocation”, Ann R Coll Surg Engl. vol. 91, (2009), pp. 2-7.

[2] R. C. Mather, L. A. Orlando, R. A. Henderson, J. T. R. Lawrence and D. C. Taylor, "A predictive model of shoulder instability after a first-time anterior shoulder dislocation”, Journal of Shoulder Elbow Surg. vol. 20, (2011), pp. 259-266.

[3] K. Horst, R. Von Harten, C. Weber, H. Andruszkow, R. Pfeifer, T. Dienstknecht and H. C. Pape, "Assessment of coincidence and defect sizes in Bankart and Hill-Sachs lesions after anterior shoulder dislocation: a radiological study", Br J Radiol. vol. 87, (2014).

[4] R. P. Donegan, G. Davis, J. Genuario and J. Bell, "The cost-effectiveness of arthroscopic Bankart repair versus non-operative treatment for first-time, traumatic, anterior shoulder dislocations", Orthop Journal of Sports Med., vol. 1, (2013).

[5] S. Zaffagnini, G. M. M. Muccioli, G. Giordano, T. Bonanzinga, A. Grassi, M. Nitri, D. Bruni, G. Ravazzolo and M. Marcacci, "Long-term outcomes after repair of recurrent post-traumatic anterior shoulder instability: comparison of arthroscopic transglenoid suture and open Bankart reconstruction", Knee Surg Sports Traumatol Arthrosc., vol. 20, (2012), pp. 816-821.

[6] M. D. Saltzman, G. S. Marecek, S. L. Edwards and D. M. Kalainov, "Infection after shoulder surgery", Journal of Am Acad Orthop Surg., vol. 19, (2011), pp. 208-218. 
[7] S. W. Svendsen, D. H. Christiansen, J. P. Haahr, L. C. Andrea and P. Frost, "Shoulder function and work disability after decompression surgery for subacromial impingement syndrome: a randomised controlled trial of physiotherapy exercises and occupational medical assistance", BMC Musculoskelet Disord. vol. 15, (2014).

[8] J. Y. Shim, M. C. Park, S. Y. Lee, M. H. Lee and H. H. Kim, "The effects of shoulder stabilization exercise and shoulder isometric resistance exercise on shoulder stability and hand function", Journal of Phys Ther Sci., vol. 22, (2010), pp. 227-232.

[9] Z. Başkurt, F. Başkurt, N. Gelecek and H. M. Özkan, "The effectiveness of scapular stabilization exercise in the patients with subacromial impingement syndrome", Journal of Back Musculoskelet Rehabil., vol. 24, (2011), pp. 173-179.

[10] S. H. Choi, J. H. Lim, H. Y. Cho, I. B. Kim, M. K. Kim and H. Y. Lee, "The effects of trunk stabilization exercise using swiss ball and core stabilization exercise on balance and gait in elderly women", Jounal of Korean Soc Phys Med., vol. 7, (2012), pp. 49-58.

[11] P. W. Marshall and B. A. Murphy, "Core stability exercises on and off a Swiss ball", Arch Phys Med Rehabil, vol. 86, (2005), pp. 242-249.

[12] A. S. de Oliveira, M. de Morais Carvalho and D. P. de Brum, "Activation of the shoulder and arm muscles during axial load exercises on a stable base of support and on a medicine ball", Journal of Electromyogr Kinesiol. vol. 18, (2008), pp. 472-479.

[13] R. Kumari, M. Verma and A. Gupta, "To determine effectiveness of closed-kinetic chain exercise on motor control and function as compared to open-kinetic chain exercise in children with spastic diplegic CP”, Indian J Physiother Occup Ther - Int J. vol. 8, (2014), pp. 33-37.

[14] K. Hayes, M. Callanan, J. Walton, A. Paxinos and G. Murrell, "Shoulder instability: management and rehabilitation", Journal of Orthop Sports Phys Ther., vol. 32, (2002), pp. 497-509.

[15] D. M. Rouleau, J. Hebert-Davies and C. M. Robinson, "Acute traumatic posterior shoulder dislocation", J Am Acad Orthop Surg., vol. 22, (2014), pp. 145-152.

[16] C. R. Bottoni, J. H. Wilckens, T. M. DeBerardino, J-C. G. D’Alleyrand, R. C. Rooney, J. K. Harpstrite and R. A. Arciero, "A prospective, randomized evaluation of arthroscopic stabilization versus nonoperative treatment in patients with acute, traumatic, first-time shoulder dislocations", Am Journal of Sports Med., vol. 30, (2002), pp. 576-580.

[17] A. S. B. Bankart, "The pathology and treatment of recurrent dislocation of the shoulder-joint", $\mathrm{Br}$ Journal Surg, vol. 26, (1938), pp. 23-29.

[18] P. M. Ludewig and J. P. Braman, "Shoulder impingement: biomechanical considerations in rehabilitation”, Man Ther., vol. 16, (2011), pp. 33-39.

[19] S. E. Sheehan, G. Gaviola, A. Sacks, R. Gordon, L. L. Shi and S. E. Smith, "Traumatic shoulder injuries: a force mechanism analysis of complex injuries to the shoulder girdle and proximal humerus", Am J Roentgenol. vol. 201, (2013), pp. 409-424.

[20] G. I. Groh, M. A. Wirth and C. A. Rockwood Jr., "Treatment of traumatic posterior sternoclavicular dislocations", Journal of Shoulder Elbow Surg., vol. 20, (2011), pp. 107-113.

[21] X. Xu, R. W. McGorry and J. Lin, "The accuracy of an external frame using ISB recommended rotation sequence to define shoulder joint angle", Gait Posture, vol. 39, (2014), pp. 662-668.

[22] M. Cricchio and C. Frazer, "Scapulothoracic and scapulohumeral exercises: a narrative review of electromyographic studies", Journal of Hand Ther. vol. 24, (2011), pp. 322-334.

[23] M. L. Voight and B. C. Thomson, "The role of the scapula in the rehabilitation of shoulder injuries", Journal of Athl Train., vol. 35, (2000), pp. 364-372.

[24] S. L. Mottram, "Dynamic stability of the scapula", Man Ther. vol. 2, (1997), pp. 123-131.

[25] A. F. Mannion, F. Caporaso, N. Pulkovski and H. Sprott, "Spine stabilisation exercises in the treatment of chronic low back pain: a good clinical outcome is not associated with improved abdominal muscle function", Eur Spine Journal, vol. 21, (2012), pp. 1301-1310.

[26] Y. H. Park, Y. B. Sung and J. H. Lee, "Effects of Swiss Ball Exercise on Functional Activity and Pain in Shoulder Dislocation Patients", ASTL, vol. 88, (2015), pp. 204-207.

[27] K. Y. Kim, S. P. Chun, T. G. Kang and G. D. Kim, "Effects of Core Stability Training on Postural Control Ability and Respiratory Function in Chronic Stroke Patients", ASTL, vol. 88, (2015), pp. 181186.

\section{Authors}

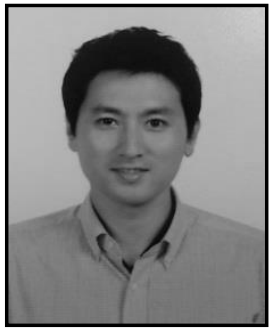

Youn-Bum Sung, he is currently a lecturer with the Department of Physical Therapy, Daegu University, Republic of Korea. His research interests include Rehabilitation, Breathing Exercises, Shoulder Disorders, and Sling Exercise. He had completed a lot of training in orthopedic and neurological Sciences Institute. Currently, he is in the doctoral program at the University of Daegu. 


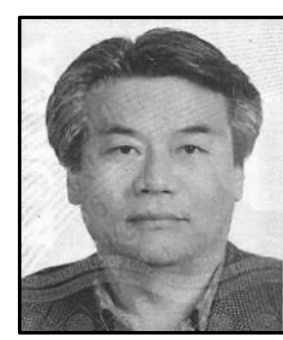

Young-Han Park, he received PhD degree from Daegu Universith, Republic of Korea. His research interests include Electrical therapy, Phototherapy, Neurophysiology, Neuroanatomy, and Sports Physiotherapy. He had completed a lot of training in orthopedic and neurological Sciences Institute. He is currently working as Professor of Department of Physical Therapy, Korea National University of Transportation, Republic of Korea.

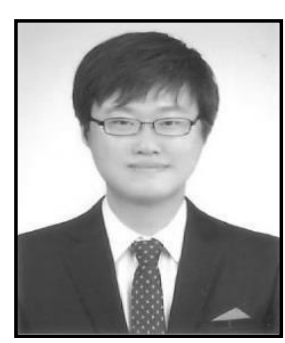

Jung-Ho Lee, he received $\mathrm{PhD}$ degree from Daegu Universith, Republic of Korea. His research interests include Shoulder Disorder, Neurophysiology, Neuroanatomy, Ergonomics, Work Physiology and Sports Physiotherapy. He had completed a lot of training in orthopedic and neurological Sciences Institute. He is currently working as Professor of Department of Physical Therapy, Kyungdong University, Republic of Korea. 